\title{
A retrospective analysis of alcohol in medico-legal autopsied deaths in Pretoria over a 1 year period
}

\author{
Ursula Ehmke *, Lorraine du Toit-Prinsloo, Gert Saayman \\ Department of Forensic Medicine, University of Pretoria, Private Bag X323, Arcadia, Pretoria 0007, South \\ Africa \\ * Corresponding author. Tel.: +27 12323 5298; fax: +27 12323 0921. E-mail addresses: \\ u.ehmke@gmail.com (U. Ehmke), lorraine.dutoit@up.ac.za (L.d. Toit-Prinsloo), gert.saayman@up.ac.za \\ (G. Saayman).
}

\begin{abstract}
The misuse of alcohol has a particularly detrimental effect and is one of the most significant public health problems in South Africa and it also has an impact on the criminal justice system with evidence of association between high levels of alcohol and risk-taking behaviour, committing crimes, or being a victim of crime. A global trend has been set worldwide with alcohol being one of the most common drugs found in post mortem specimens and especially with regards to cases admitted for medico-legal autopsies. The influence of alcohol on the cause of death is either a contributory or an underlying factor in a substantial number of violent deaths. We retrospectively reviewed 1455 cases, in which alcohol was taken, of 2344 medicolegal autopsies done in 2009 . We found that $47 \%$ of the cases tested positive for alcohol, with the reported blood alcohol concentrations varying from 0.01 to $0.95 \mathrm{~g}$ per $100 \mathrm{ml}$ (mean $=0.16$ $\pm 0.11 \mathrm{~g}$ per $100 \mathrm{ml}$ ) with the highest proportion being in the $0.10-0.19 \mathrm{~g}$ per $100 \mathrm{ml}$ range. A breakdown of the results showed that road traffic accidents, assaults and firearm-related deaths predominated the alcohol-positive cases. The results showed that there was a definite correlation between alcohol consumption and the incidence of other that natural deaths.
\end{abstract}

KEYWORDS: alcohol, medico-legal autopsy, road traffic accidents, firearm-related deaths, assaults

\section{Introduction}

The consumption of alcohol is an almost universal phenomenon and its abuse often leads to drunkenness and violence. [1,2] It is well known that the use of alcohol increases the risk of dying from unnatural or violent causes, as acute intoxication may compromise rational thinking and decreases motor and sensory function, whilst also leading to increased risk taking behaviour, aggression and self-destructive tendencies. $[1,3]$.

The misuse of alcohol has a particularly detrimental effect and is one of the most significant public health problems in South Africa and it also has an impact on the criminal justice system, with evidence of association between high levels of alcohol and risk-taking behaviour, 
committing crimes, or being a victim of crime [4-6]. Studies have shown that alcohol is also the preferred substance of abuse $[4,7]$.

In a country with a population in excess of 45 million people, it is estimated that well over 6 billion litres of alcoholic beverages are consumed by South Africans per year [2,8]. It is well documented that a high level of alcohol misuse exists among residents of disadvantaged communities with binge drinking among young males being exceptionally high. South Africa is also known to be one of the higher alcohol-consumption nations with absolute alcohol consumption for adults ranging between 9 and 10 litres per year [9]. The widespread misuse and abuse of alcohol in South Africa is likely to have a profound impact on the economy, with alcohol abuse estimated to cost South Africa well over R9 billion per year (approximately $\$ 840$ million USD) [2].

Risky drinking patterns are common in South Africa, but the biggest concern remains the high level of heavy episodic drinking (binge drinking) linked to many countries with middle to high per capita consumption, such as Brazil and South Africa. In some European countries, such as France with high adult per capita consumption (APC) (13.7 litres per year), heavy episodic drinking is relatively low, indicating that APC can be driven by more regular but moderate drinking patterns [10].

A global trend has been set worldwide, with alcohol being one of the most common drugs found in post mortem specimens and especially with regard to cases admitted for medico-legal autopsy [11,12]. The influence of alcohol on the cause of death is either a contributory or an underlying factor in a substantial number of violent deaths [13]. It is of utmost importance to continue to raise the community's awareness of the harmful and potentially fatal effects of alcohol, in order to prevent future fatalities [14].

A thorough literature review indicates that there is minimal statistical data pertaining to alcohol and non-natural deaths in South Africa, and none were found for any part of the Gauteng province, as opposed to the abundance of data available from other countries. We compared our results to two studies done locally, both done in the Western Cape. We also made comparisons against studies done in Sweden, Ireland, Slovenia, Brazil and Jordan.

The aim of this study was to review the alcohol levels in medico-legal investigations of unnatural deaths in Pretoria from 01/01/2009 to 31/12/2009. Emphasis was placed on the alcohol level obtained in blood/fluid samples harvested at autopsy and the relevance thereof to the cause of death. Concurrently comparisons were drawn to the parameters at hand (demographics, cause of death, and laboratory analysis) and to find trends in alcohol consumption and other drug or poison usage.

\section{Materials and Methods}

The Pretoria Medico-Legal Laboratory (PMLL) serves the greatest part of the City of Tshwane Metropolitan Municipality, which had a population of about 2.4 million people in 2007, and is located in the administrative capital of South Africa, Pretoria [15]. 
At the PMLL, alcohol is routinely taken during the post mortem examination on all other than natural deaths admitted to this facility if the deceased is 14 years or older and the autopsy takes place, preferably, within 24 hours of the external cause/circumstance of the death.

A retrospective descriptive study was carried out on all case files of non-natural deaths, in which samples were taken for alcohol analysis, on which autopsies have been done at the PMLL from $01 / 01 / 2009$ to $31 / 12 / 2009$.

During autopsy, blood samples are collected into sealed post mortem blood alcohol kits which includes a McCartney bottle that contains $0.32 \mathrm{mg}$ sodium fluoride (as preservative) and potassium oxalate (as anticoagulant) in a ratio of 4.3:1. The McCartney bottles are resealed in their polystyrene containers and sent to the laboratory for blood alcohol analysis.

All the samples were analysed by the Pretoria Forensic Chemistry Laboratory. Ethanol concentrations were determined by headspace gas chromatography with flame ionization detector. All results presented in this study were the average of duplicate analyses. An Agilent 6890 gas chromatograph (GC) system with flame ionisation detector and an Agilent G1888 headspace auto sampler was used throughout this study. The GC operates under a detector temperature of $220^{\circ} \mathrm{C}$ and oven temperature of $80^{\circ} \mathrm{C}$ while the auto sampler operates under a detector temperature of $300^{\circ} \mathrm{C}$ and oven temperature of $145^{\circ} \mathrm{C}$. The chromatographic columns were a Porapak-type HP-ALC ( $7 \mathrm{~m}$ and $0.32 \mathrm{~mm}$ internal diameter, with a film thickness of 20 um) and a Polyethylene glycol-type DB-ALC1 (30 $\mathrm{m}$ and $0.53 \mathrm{~mm}$ internal diameter, with a film thickness of $3 \mathrm{um}$ ) respectively. Nitrogen was used as carrier gas with a flow rate of $3.6 \mathrm{ml}$ per $\min (\mathrm{GC})$ and $31.7 \mathrm{ml}$ per min (auto sampler).

The internal standard solution was prepared from $1 \mathrm{ml}$ t-butanol prepared in deionised water to give a concentration of $0.1 \%(\mathrm{v} / \mathrm{v})$. Certified reference ethanol standards at concentrations of $0.01,0.02,0.05,0.1,0.2,0.3,0.5 \mathrm{~g}$ per $100 \mathrm{ml}$ were used as calibrators. All standards were purchased from the National Metrology Institute of South Africa (NMISA).

The total number of cases (caseload) admitted to the PMLL was recorded as well as the total number of cases from which samples for alcohol analysis were taken. Information was collected on the blood alcohol concentration (BAC); demographic details of the deceased including age, gender and race; any additional noteworthy details on the history; the scope of the post mortem examination and the cause of death.

The data was collected on a data sheet and transferred to a Microsoft ${ }^{\circledR}$ Office Excel $^{\circledR} 2007$ (Microsoft, Redmond, Washington, US) spread sheet. The data was then transferred to the STATA $10^{\circledR}$ (StataCorp LP, Texas, USA) program and analysed in conjunction with a statistician.

Ethics Committee approval was obtained from the Research Ethics Committee of the Faculty of Health Sciences at the University of Pretoria prior to the commencement of the study. 
Unless otherwise stated, alcohol levels refer to blood alcohol levels and are expressed in grams per 100 millilitres of blood. A blood alcohol concentration of $0.01 \mathrm{~g}$ per $100 \mathrm{ml}$ is considered to be positive.

\section{Results}

A total caseload of 2344 was admitted to the PMLL for 2009. From this number, 1455 samples were taken for alcohol analysis. This constitutes $62 \%$ of the total caseload. Alcohol results were available in 1431 of the 1455 cases analysed, 24 cases still had pending results at the time of data collection and positive values were obtained in $686(47 \%)$ of the cases, which constitutes $29 \%$ of the total caseload. The average blood alcohol concentration (BAC) was $0.16 \pm 0.11 \mathrm{~g}$ per $100 \mathrm{ml}$ which ranged from $0.01-0.95 \mathrm{~g}$ per $100 \mathrm{ml}$ (Fig. 1).

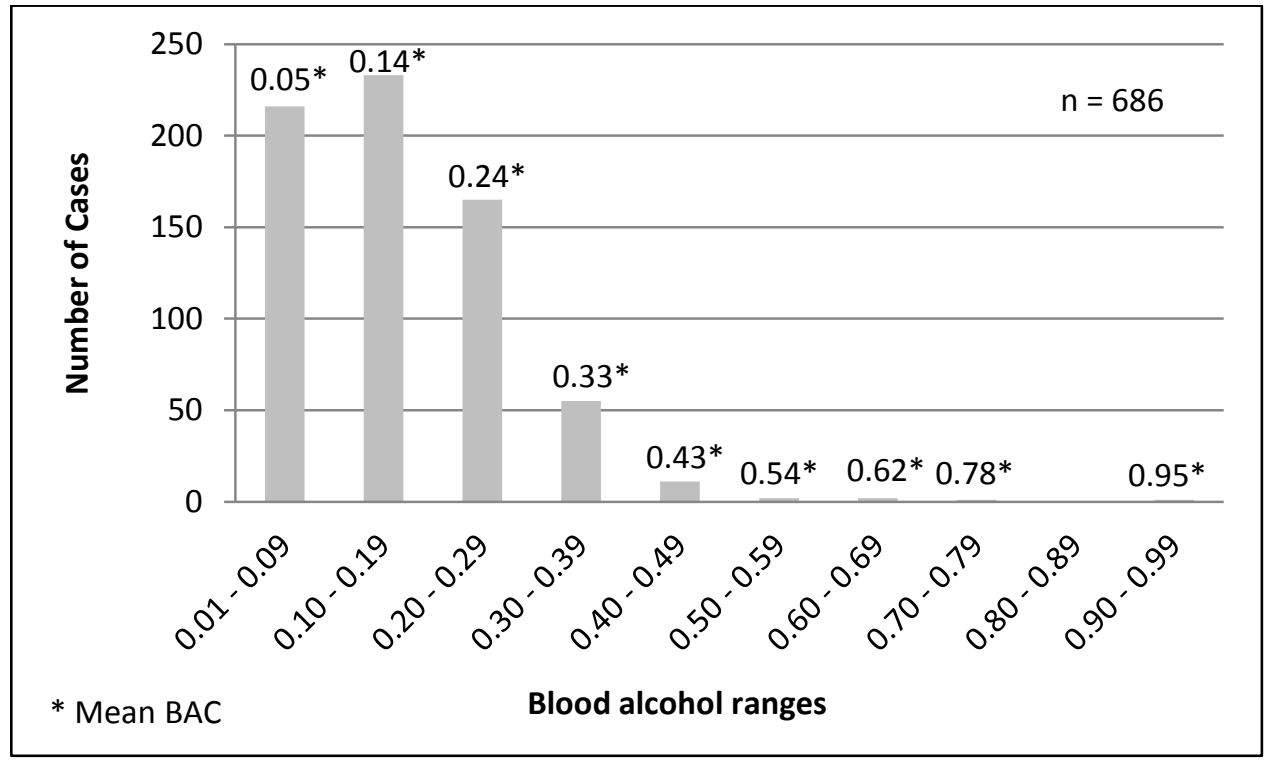

Fig. 1: Distribution of positive alcohol levels (in g per 100ml)

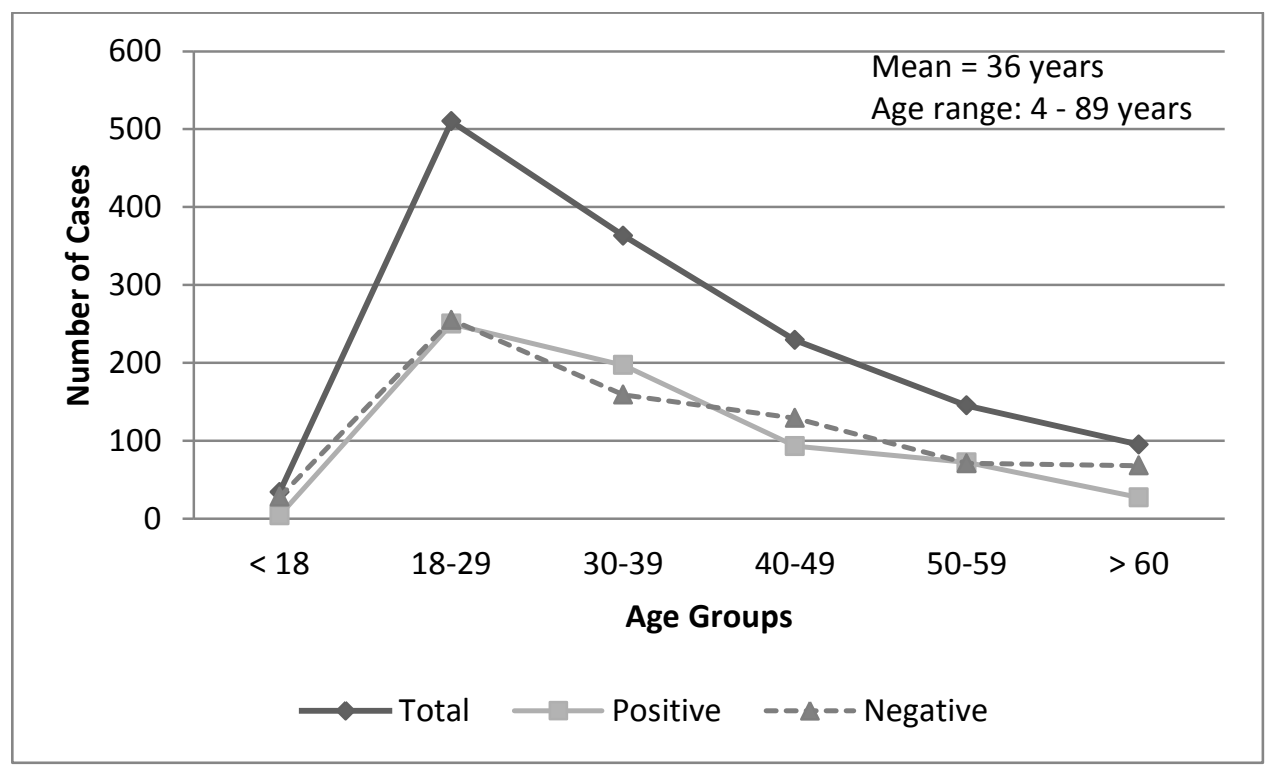

Fig. 2: Age distribution 


\subsection{Age Distribution (Fig. 2)}

Of the 1455 cases, the largest single group was $18-29$ years old, although the mean age was found to be 36 years (range $=4-89$ years). For age groups $<18,40-49$ and $60+$ years old, more negative than positive cases were found, while the converse was true for the $30-39$ year group. In the case of the $18-29$ and $50-59$ groups, there were equal numbers of positive and negative cases.

\subsection{Gender Distribution}

Most of the decedents examined $(81 \%, \mathrm{n}=1173)$ were male and just over half of them were positive $(51 \%, n=595)$ with a mean BAC of 0.16 g per $100 \mathrm{ml}$. In contrast, only $32 \%(n=91)$ of the female decedents were positive with a mean BAC of $0.14 \mathrm{~g}$ per $100 \mathrm{ml}$.

\subsection{Racial Distribution}

One-thousand-and-forty-seven (72\%) of the deceased individuals were found to be black, 355 (24\%) were white, 33 (2\%) were coloured, 9 (1\%) were Asian/Indian and in $11(1 \%)$ the race was unknown. Decedents from the coloured and black community also had a higher incidence of positive values ( $52 \%$ and $48 \%$ respectively), followed by $43 \%$ for the white community.

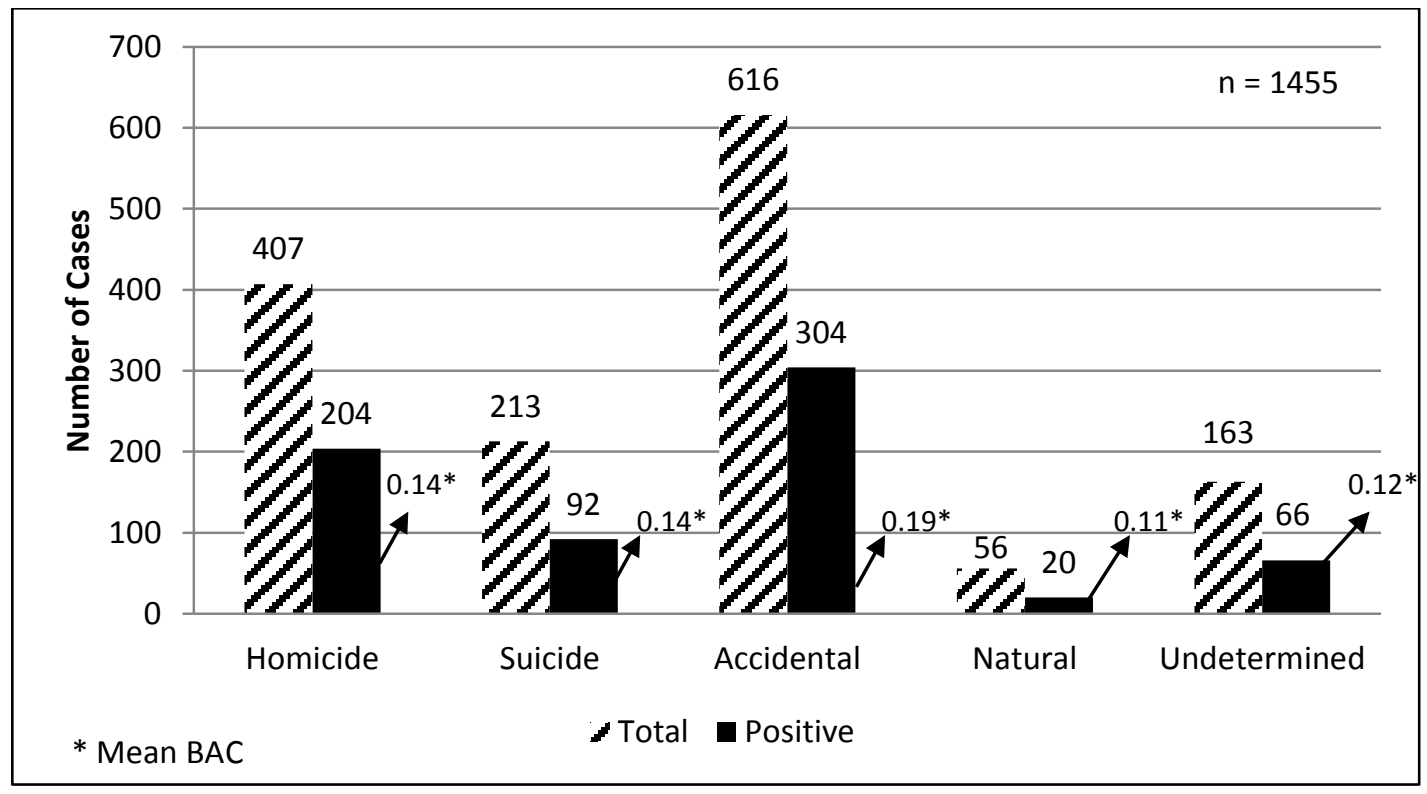

Fig. 3: Manner of death

\subsection{Apparent Manner of Death (Fig. 3)}

In South Africa, the manner of death is not determined by the forensic pathologist as, according to the Inquests Act 58 of 1959 this function belongs to the presiding officer, but during the post mortem examination, the pathologist will make an indication as to the apparent manner of death, purely for statistical purposes [16]. The categories to describe the apparent manner of 
death include: natural, accidental, homicide, suicide and undetermined. In the accidental group, 304 (49\%) of the 616 cases tested positive for alcohol. Alcohol was present in 204 (50\%) of the 407 homicide cases. This was the only group in which the number of positive cases outnumbered the negative cases. Of the 213 cases of suicide, alcohol was present in 92 (43\%) cases.

\subsection{Date of Death}

No significant finding was found regarding the number of positive cases within each month of 2009 , having the least amount of positive decedents $(39 \%, n=52)$ in May and the most $(57 \%, n$ $=75)$ in October.

\subsection{Scene of Injury}

Six-hundred-and-twenty-four (43\%) of the 1455 incidents took place on a road with 333 being positive (with a mean BAC of $0.18 \mathrm{~g}$ per $100 \mathrm{ml}$ ), 225 (16\%) occurred in informal settlements and $216(15 \%)$ of the incidents occurred in private homes, which corroborate with the apparent manner of death. Of those occurring in informal settlements, $56 \%(n=126)$ tested positive with a mean BAC of $0.16 \mathrm{~g}$ per $100 \mathrm{ml}$ while private homes indicated positivity in $42 \%(n=91)$ with a mean BAC of $0.15 \mathrm{~g}$ per $100 \mathrm{ml}$.

Table 1: Percentage of cases found positive for blood alcohol classified by cause of death and mean BAC

\begin{tabular}{|c|c|c|c|c|c|}
\hline Cause / Circumstances of Death & Total Cases & Positive Cases & \% Positive & Mean $\mathrm{BAC}^{\mathrm{a}}$ & Cases $>0.05$ \\
\hline Firearm discharge & 238 & 99 & 42 & 0.13 & \\
\hline$*$ Homicidal $^{\mathrm{b}}$ & 181 & 74 & 41 & 0.12 & \\
\hline * Suicidal $^{\mathrm{b}}$ & 52 & 22 & 42 & 0.16 & \\
\hline * Undetermined ${ }^{\mathrm{b}}$ & 5 & 3 & 60 & 0.11 & \\
\hline Sharp force & 111 & 81 & 73 & 0.17 & \\
\hline Blunt force & 90 & 34 & 38 & 0.13 & \\
\hline Other assaults & 35 & 15 & 43 & 0.16 & \\
\hline Hanging & 125 & 55 & 44 & 0.13 & \\
\hline Poisoning (ingestion \& gassing) & 69 & 28 & 41 & 0.15 & \\
\hline Burn & 35 & 18 & 51 & 0.22 & \\
\hline$M A^{c}$ pedestrian & 232 & 129 & 56 & 0.22 & 117 \\
\hline MVA passenger & 101 & 40 & 40 & 0.11 & 30 \\
\hline MVA driver & 119 & 75 & 63 & 0.17 & 67 \\
\hline MVA unspecified & 50 & 21 & 42 & 0.16 & 15 \\
\hline Bicycle, motor cycle & 35 & 16 & 46 & 0.17 & 15 \\
\hline Other & 215 & 75 & 35 & 0.14 & \\
\hline Total & 1455 & 686 & 47 & 0.16 & \\
\hline
\end{tabular}

\footnotetext{
${ }^{a}$ BAC: blood alcohol concentration

${ }^{\mathrm{b}}$ Breakdown of firearm discharges into manner of death

${ }^{\mathrm{c}} \mathrm{MVA}$ : motor vehicle accident
} 


\subsection{Cause / Circumstances of Death (Table 1)}

For simplification, we established the following categories to describe the cause or circumstance of death: road traffic accidents (RTAs), assaults, firearm discharges, hangings, poisoning (ingestion and gassing), burns and the rest were grouped together under other causes. The Pearson Chi-Square statistic $(24.736, P<0.0001)$ indicates that there seems to be a statistically significant association between the cause of death categories and the outcome (positive or negative) of the BAC. The standardised residual for the "other causes" category (-2.3 and 2.2) indicate that fewer individuals who died from "other causes" tested positive for alcohol than was expected under the model, whereas, more tested negative for alcohol than was expected.

\subsubsection{Road Traffic Accidents}

There were 537 (37\%) RTA fatalities out of the 1455 cases examined, and they were divided into: motor vehicle drivers, motor vehicle passengers, pedestrians, cyclists (bicycles and motorbikes) and unknown. Alcohol was present in 281 (52\%) of the 537 RTAs. Seventy-five (63\%) of the 119 drivers tested positive for alcohol, with a mean BAC of $0.17 \pm 0.09 \mathrm{~g}$ per $100 \mathrm{ml}$, and $89 \%(\mathrm{n}=$ 67) of these had a BAC over $0.05 \mathrm{~g}$ per $100 \mathrm{ml}$. Forty (40\%) of the 101 passengers and 21 (42\%) of the 50 unknown cases had positive BACs with means of $0.11 \pm 0.08 \mathrm{~g}$ per $100 \mathrm{ml}$ and $0.16 \pm$ $0.18 \mathrm{~g}$ per $100 \mathrm{ml}$ respectively. Of the 232 pedestrian cases, alcohol was found in 129 (56\%, mean $=0.22 \pm 0.11 \mathrm{~g}$ per $100 \mathrm{ml})$ of the cases. Out of the 35 cyclists, $16(46 \%$, mean $=0.17 \pm$ $0.08 \mathrm{~g}$ per $100 \mathrm{ml}$ ) tested positive. The $\chi^{2}$ standardised residual values for RTAs (-1.7 and 1.7) indicated that more individuals who died as a result of a RTA tested positive for alcohol than was expected under the model, whereas, fewer individuals tested negative for alcohol than was expected.

\subsubsection{Firearm Discharges}

Of the 238 cases of deaths related to firearm discharges, which include two cases where blunt force injuries and burns were also sustained respectively, 99 (42\%) tested positive for alcohol. Firearm-related deaths were categorised according to manner of death either as homicide, suicide or undetermined. Homicidal firearm discharges totalled 181 cases and 74 (41\%) tested positive whereas suicides totalled 52 cases and $22(42 \%)$ tested positive.

\subsubsection{Assaults}

In this group, 130 (56\%) of the 236 cases tested positive for alcohol. Assaults were subdivided into 4 subgroups: blunt force; sharp force; strangulation, suffocation, asphyxia and a combination of the aforementioned. Eighty-one (73\%) of the 111 cases of sharp force, 34 (38\%) of the 90 cases of blunt force and $15(43 \%)$ of the 35 cases of other assaults tested positive for alcohol. The $\chi^{2}$ standardised residual values for assaults (-1.7 and 1.8) indicated that more individuals who died as a result of an assault tested positive for alcohol than was expected under the model, whereas, fewer individuals tested negative for alcohol than was expected.

\subsection{Additional Toxicological Analysis}

In 1439 cases blood samples (mostly peripheral blood) were taken for alcohol analysis and in 
6 of these cases, additional specimens -3 urine, 2 vitreous humour and 1 urine and vitreous humour samples - were taken to determine the alcohol level. In 6 cases only muscle samples were sent for alcohol analysis and in 1 case both muscle and vitreous humour were sent for analysis. One-hundred-and-seventy-eight (12\%) samples were sent for toxicological analysis (licit drugs; illicit drugs and poisons, such as carbon monoxide) in addition to the alcohol analysis, but results for only 62 of the cases were available at the time of data collection.

\section{Discussion}

Alcohol-related death, illness and injury is one of the largest public health issues facing South Africa today $[1,4]$.

Our review showed that alcohol was present in $47 \%$ of unnatural deaths that were tested for alcohol. There is no obvious reason to conclude that cases excluded from sampling would have a different result profile would they have been tested. The largest proportion of cases $(34 \%, n=$ 233) were in the $0.10-0.19 \mathrm{~g}$ per $100 \mathrm{ml} \mathrm{BAC}$ range.

Our results compared well with a study done by Loftus and Dada [1] in Cape Town (1985 - 1989) who found that $52 \%(n=498$ ) of cases tested positively for alcohol, a study done by Ingoldsby and Callagy [17], from 2003 to 2007, in the West of Ireland who also found that 52\% ( $n=162$ ) tested positive and a study done by Campelo and Caldas in Brazil from 2006 to 2008 [18], who reported a $47 \%$ positivity $(n=1116)$.

We compared our results of apparent manner of death to that of Loftus and Dada [1] and a study by Skibin et al. in Ljubljana (2004) [3]. Loftus and Dada reported positive findings for $66 \%$ of the 477 homicides and $29 \%$ of the 34 suicides, whereas Skibin et al. reported positivity in $29 \%$ of homicides and $25 \%$ of suicides. Our study indicated that alcohol was present in $50 \%$ of the 407 homicides, and $43 \%$ of the 213 suicides, which does not correlate well with these studies.

Accidental deaths were the most common manner of death in the 1455 cases of our study and alcohol was present in $49 \%$, and most of them were due to RTAs. Alcohol was present in 281 (52\%) of the 537 RTAs, and our findings are comparable to those of Ingoldsby and Callagy [17], who found that $51 \%$ of their 74 RTAs tested positive. Our study and those from Ingoldsby and Callagy showed slightly higher numbers than those from Loftus and Dada [1] and a study done by Bellis et al. in Cork city and county in 2003 - 2004 [14], where alcohol was associated with $41 \%$ and $40 \%$ of RTAs, respectively. Similar findings were also found in a study done by Le Roux and Smith [19] in the Cape Peninsula (1962), who reported that $36 \%$ of their 226 RTAs tested positive for alcohol. A study done by Sjögren et al. [20] in Sweden (1992 - 1996) reported much lower alcohol involvement, with only $663(26 \%)$ of the 2508 cases of RTAs testing positive. Some factors that can account for this is Sweden's strict policy against drunk driving and the fact that they have one of the lowest legal limits in the world [20].

Although pedestrians ranked highest (43\%) of all RTA victims, drivers were found to have the highest incidence (63\%) of testing positive for alcohol, which is similar to the studies done in Ireland (Bellis and Ingoldsby) [14,17] and a study done in 2007 by Etab et al. in Jordan [21]. 
Currently, in South Africa, a BAC of $0.05 \mathrm{~g}$ per $100 \mathrm{ml}(0.02 \mathrm{~g}$ per $100 \mathrm{ml}$ for professional drivers) is the legal limit for driving a vehicle, as stated in section 65 of the National Road Traffic Act 93 of 1996 [22]. It is therefore important to note that in 67 (89\%) driver fatalities in our study, the BAC was $>0.05 \mathrm{~g}$ per $100 \mathrm{ml}$, with the mean BAC of $0.17 \pm 0.09 \mathrm{~g}$ per $100 \mathrm{ml}$ found among this group being far in excess of the legal limit. It is reasonably clear that the risk of becoming involved in a RTA is increased from a BAC of $0.05 \mathrm{~g}$ per $100 \mathrm{ml}[23,24]$, although there is cohesive evidence to support that driving ability can be impaired from any BAC above zero $[25,26]$. It is alarming to note that there are now more people than documented in the 1962 [19] and 1985 to 1989 [1] studies who abuse alcohol and are subsequently involved in fatal RTAs, even though the legal alcohol limit for driving was reduced from $0.08 \mathrm{~g}$ per $100 \mathrm{ml}$ to $0.05 \mathrm{~g}$ per $100 \mathrm{ml}$ in 1996 [22].

Unfortunately no deductions could be made regarding the relationship between alcohol use in combination with other drugs or poisons due to most of these cases having outstanding toxicology results at the time of data collection. It is also significant to note that samples other than blood being sent for alcohol analysis and routine testing for other drugs or poisons are not common practice among pathologists at the PMLL.

The results show that there is a statistically significant association between alcohol consumption and the incidence of other than natural deaths $\left(\chi^{2}=24.736, P<0.0001\right)$. Findings' regarding RTAs were of note, and requires urgent attention, as many of these deaths could possibly have been avoided.

\section{Conclusion}

In conclusion, this study shows alcohol is an important factor in all types of unnatural deaths and is involved in $47 \%$ of medico-legal deaths in Pretoria.

It is important to note that this is the first study of its kind published in the last 10 years in South Africa, and there is a significant difference in our population figures as opposed to the referenced studies.

Alcohol involvement can be seen in about $50 \%$ of adult persons that die within 12 to 24 hours of being involved in an incident, but this figure is grossly underrepresented.

Alcohol was involved in about $50 \%$ of homicides, suicides and accidental deaths; and deaths due to natural causes also had a high level of alcohol involvement (36\%).

In $89 \%$ of drivers that tested positive for alcohol the BAC was $>0.05 \mathrm{~g}$ per $100 \mathrm{ml}$ and there is an apparent increase in alcohol involvement in RTAs over time.

We hope that this study will serve as a benchmark for future research as it is important for our social culture to continue to repeat these types of studies on a continuous basis.

\section{References}

[1] I.A. Loftus, M.A. Dada, A retrospective analysis of alcohol in medicolegal postmortems over a period of five years, Am. J. Forensic Med. Pathol. 13 (1992) 248-252. 
[2] M. Schneider et al., Estimating the burden of disease attributable to alcohol use in South Africa in 2000, S. Afr. Med. J. 97 (2007) 664-672.

[3] L. Skibin, M. Bilban, J. Balazic, Harmful alcohol use of those who died a violent death (the extended region of Ljubljana 1995-1999), Forensic Sci Int. 147 (2005) S49-52.

[4] W. Pick, S. Naidoo, F. Ajani, V. Onwukwe, R. Hansia, O. Bielu, Prevalence of alcohol and cannabis use and reported knowledge, attitudes and practice regarding its relationship with health, Wits School of Public Health. 1 (2003) 1-85.

[5] B. Myers, C. Parry, Fact sheet: Alcohol use in South Africa - Alcohol and Drug Abuse Research Group, Medical Research Council (MRC). [Online]. 2003. [cited 30 Sep 2013]. Available from: http://www.sahelathinfo.org/admodule/alcohol.htm.

[6] World Health Organization. Alcohol and Interpersonal Violence. [Online]. 2005. [cited 15 Nov 2013]. Available from:

http://www.who.int/violenceprevention/publications/policy briefing alcohol and interperson al violence.pdf.

[7] D. Fourie, Portfolio of clients in treatment, Fourth report: April 2008 - March 2009. South African National Council on Alcoholism and Drug Dependence, (SANCA) 2009.

[8] Statistics South Africa, Mid-year population estimates 2009. Statistical release P0302. Pretoria, 2009. [cited 30 Sep 2013] Available from:

http://www.statssa.gov.za/publications/P0302/P03022009.pdf

[9] C.D.H. Parry, Substance abuse in South Africa: Country report on young persons. Prepared for the WHO/UNDCP Regional Consultation - Global initiative on primary prevention on substance abuse among young people, Medical Research Council (MRC), Harare, Zimbabwe (1998) 1-26.

[10] World Health Organization, Global status report on alcohol and health. [Online]. 2011. [cited 15 Nov 2013] Available from:

http://www.who.int/substance abuse/publications/global alcohol report/msbgsruprofiles.pdf

[11] V.A. Boumba, N. Kourkoumelis, K.S. Ziavrou, K. Fragkouli, T. Vougiouklakis, Patterns of the most abundant volatiles detected in post-mortem blood, Rom J Leg Med. 20 (2012) 147-154.

[12] F.C. Kugelberg, A.W. Jones, Interpreting results of ethanol analysis in postmortem specimens: A review of the literature, Forensic Sci Int. 165 (2007) 10-29.

[13] I. Nordrum, T.J. Eide, L. Jørgensen, Alcohol in a series of medico-legally autopsied deaths in northern Norway 1973-1992, Forensic Sci. Int. 110 (2000) 127-137. 
[14] M. Bellis, M.A. Bolster, C.T. Doyle, The role of alcohol in deaths presenting to the coroner's service in Cork city and county, Ir. Med. J. 102 (2009) 13-15.

[15] Statistics South Africa, Community Survey 2007: Basic Results - Gauteng, Pretoria, 2009. [cited 23 Dec 2013] Available from: http://www.statssa.gov.za/Publications/Report-03-01-272007.pdf

[16] Department of Justice, Inquests Act No. 58 of 1959, Statutes of the Republic of South Africa [statute on the Internet], [cited 2013 Sep 30], Available from: http://www.justice.gov.za/legislation/acts/1959-58.pdf.

[17] H. Ingoldsby, G. Callagy, Alcohol and unnatural deaths in the West of Ireland: a 5-year review, J. Clin. Pathol. 63 (2010) 900-903.

[18] E.L.C. Campelo, E.D. Caldas, Postmortem data related to drug and toxic substance use in the Federal District, Brazil, from 2006 to 2008, Forensic Sci. Int. 200 (2010) 136-140.

[19] L.C. Le Roux, L.S. Smith, Violent deaths and alcoholic intoxication, J. Forensic Med. 11 (1964) 131-47.

[20] H. Sjögren, A. Eriksson, K. Ahlm, Alcohol and unnatural deaths in Sweden: A medico-legal autopsy study, J. Stud. Alcohol 61(2000) 507-514.

[21] T.K. Etab, M.A. Emad, S.H. Mu'men, Prevalence of alcohol in autopsied medico-legal cases at the National Institute of Forensic Medicine, Jordan, J. Toxicol. Environ. Health Sci. 3 (2011) 264 270.

[22] Department of Transport, National Road Traffic Act No. 93 of 1996, Statutes of the Republic of South Africa, Government Gazette [statute on the Internet], [cited 2013 Sep 30], Available from: http://www.info.gov.za/gazette/acts/1996/a93-96.htm.

[23] Council on Scientific Affairs, Alcohol and the driver, J. Am. Med. Assoc. 255 (1986) 522-527.

[24] A.F. Moynham, J. Perl, S.G. Anderson, S.R. Jennings, G.A. Starmer, Evidential breath analysis in New South Wales: an exercise in pragmatism, in: Alcohol, Drugs and Traffic Safety, C.N. Kloeden, A.J. McLean (Eds.), National Health and Medical Research Council Road Accident Research Unit, Adelaide, pp. 129-133.

[25] H. Moskowitz, C.D. Robinson, Effects of low doses of alcohol on driving-related skills: A review of the evidence, Report No: DOT-HS-807 280, U.S. Department of Transportation, Washington, D.C., 1988.

[26] N.G. Flanagan, P.W. Strike, C.J. Rigby, G.K. Lochridge, Effects of low doses of alcohol on driving performance, Med. Sci. Law 23 (1983) 203-208. 